\title{
Cryptic variation in an ecological indicator organism: mitochondrial and nuclear DNA sequence data confirm distinct lineages of Baetis harrisoni Barnard (Ephemeroptera: Baetidae) in southern Africa
}

Lyndall L Pereira-da-Conceicoa ${ }^{1 *}$, Benjamin W Price ${ }^{1,2,3}$, Helen M Barber-James ${ }^{1,2}$, Nigel P Barker ${ }^{4}$, Ferdy C de Moor ${ }^{1,2}$ and Martin $\mathrm{H}_{\text {Villet }}{ }^{1}$

\begin{abstract}
Background: Baetis harrisoni Barnard is a mayfly frequently encountered in river studies across Africa, but the external morphological features used for identifying nymphs have been observed to vary subtly between different geographic locations. It has been associated with a wide range of ecological conditions, including $\mathrm{pH}$ extremes of pH 2.9-10.0 in polluted waters. We present a molecular study of the genetic variation within B. harrisoni across 21 rivers in its distribution range in southern Africa.

Results: Four gene regions were examined, two mitochondrial (cytochrome c oxidase subunit I [COI] and small subunit ribosomal 16S rDNA [16S]) and two nuclear (elongation factor 1 alpha [EF1a] and phosphoenolpyruvate carboxykinase [PEPCK]). Bayesian and parsimony approaches to phylogeny reconstruction resulted in five wellsupported major lineages, which were confirmed using a general mixed Yule-coalescent (GMYC) model. Results from the EFla gene were significantly incongruent with both mitochondrial and nuclear (PEPCK) results, possibly due to incomplete lineage sorting of the EFla gene. Mean between-clade distance estimated using the $\mathrm{COI}$ and PEPCK data was found to be an order of magnitude greater than the within-clade distance and comparable to that previously reported for other recognised Baetis species. Analysis of the Isolation by Distance (IBD) between all samples showed a small but significant effect of IBD. Within each lineage the contribution of IBD was minimal. Tentative dating analyses using an uncorrelated log-normal relaxed clock and two published estimates of $\mathrm{CO}$ / mutation rates suggest that diversification within the group occurred throughout the Pliocene and mid-Miocene ( 2.4-11.5 mya).
\end{abstract}

Conclusions: The distinct lineages of $B$. harrisoni correspond to categorical environmental variation, with two lineages comprising samples from streams that flow through acidic Table Mountain Sandstone and three lineages with samples from neutral-to-alkaline streams found within eastern South Africa, Malawi and Zambia. The results of this study suggest that $B$. harrisoni as it is currently recognised is not a single species with a wide geographic range and $\mathrm{pH}$-tolerance, but may comprise up to five species under the phylogenetic species concept, each with limited $\mathrm{pH}$-tolerances, and that the B. harrisoni species group is thus in need of taxonomic review.

\footnotetext{
* Correspondence: lyndall.pereira@gmail.com

'Department of Zoology and Entomology, Rhodes University, P.O. Box 94

Grahamstown, 6140, South Africa

Full list of author information is available at the end of the article
} 


\section{Background}

It is axiomatic that successful applied biology relies on sound taxonomy. For instance, the success of biomonitoring depends in part on the correct identification of the indicator organisms involved [1]. Mayflies are known to be important indicator species in aquatic biomonitoring (e.g. [2-5]). Amongst these, two species of mayflies in the genus Baetis Leach stand out in importance: $B$. rhodani Pictet in Europe (e.g. [6-8]), and B. harrisoni Barnard in southern Africa (e.g. [2,9-11]). Baetis rhodani has long been recognised as a complex of cryptic species (see [12] for a review). The research on B. harrisoni presented here investigates whether this species may be similar to B. rhodani in terms of its widespread distribution and range of ecological tolerances, and whether it also represents a number of cryptic species.

Baetis harrisoni is a physically robust species, with nymphs found in slow- to fast-flowing $\left(0.1-1.0 \mathrm{~ms}^{-1}\right)$ streams and rivers throughout sub-Saharan Africa [13]. It has also been recorded in polluted waters ranging in $\mathrm{pH}$ from about 2.9 to $10.0[9,14]$. Such a broad geographical distribution and variation in environmental tolerance in an organism with dubious dispersal ability suggests that there may be cryptic species associated with the name. A third line of evidence that $B$. harrisoni may constitute more than one species is that the morphological features used to identify its nymphs (e.g. mouthpart structure, abdominal pigmentation and relative size of gills) have been observed to vary subtly between populations in different geographic locations. Baetis harrisoni is therefore worth studying as a species of practical significance but uncertain taxonomy.

The use of molecular (DNA) data in resolving cryptic lineages has at least four advantages. Firstly, DNA data facilitate the detection of cryptic species because they provide more direct evidence of population genetic processes like interbreeding than do morphological data, and often with greater precision. For example, recent studies using the mitochondrial cytochrome $c$ oxidase $I$ $(C O I)$ gene showed that the name B. rhodani was applied to at least nine morphologically cryptic haplogroups [15] and that in Finland the species B. macani Kimmins and $B$. vernus Curtis are both paraphyletic in terms of their COI gene phylogenies [16]. Secondly, molecular markers provide a valuable benchmark against which morphological characters for each lineage can be sought, and facilitate the interpretation of morphological variability. A re-analysis of morphological characters of the nymphs of $B$. macani (following a molecular study) provided diagnostic markers for identification of some lineages identified by DNA haplotypes [16]. Thirdly, DNA data facilitate the association of conspecific immature and adult stages in life-cycles that feature radical metamorphosis and this has been done successfully in some mayflies [17]. Finally, by helping to resolve questions of relationship amongst specimens from different places with greater precision, molecular markers can provide information about historical and geographical processes that underlie diversity.

Mitochondrial DNA sequences (especially of the COI region) provide useful data for addressing the types of challenges raised here [15,16,18]. However, numerous critiques of the taxonomic use of this gene [19-23] emphasise the need to cross-validate phylogenies with data from additional nuclear genes. This need arises from the possibility of incomplete lineage sorting, horizontal gene transfer, introgression and population fragmentation effects [24]. For example, two specimens identified by their morphology as members of B. macani and B. liebenauae Keffermüller, respectively, were identified as $B$. vernus using $C O I$-based phylogenetic analysis, suggesting mitochondrial introgression [16]. Previous molecular taxonomic studies of Baetis species [15,16] have used only mitochondrial sequence data.

Our study has two aims. First, it provides a molecular study of the genetic variation within $B$. harrisoni across its distribution range in southern Africa using four genes (COI, 16S, PEPCK and EF1 $\alpha$ ). Second, it explores two nuclear genes (PEPCK and EF1 $\alpha$ ) as additional nuclear DNA markers to cross-validate the results of $C O I$ data, given recent critiques of using this region in isolation.

\section{Methods}

\section{Taxon sampling}

Our sampling strategy was driven by seeking cryptic variation where one is most likely to find it. Baetis harrisoni occurs throughout the south and east of South Africa (Albany Museum records: Figure 1), in biomes and climates that vary from Mediterranean (with winter rainfall) in the southwest Cape Floristic Region to temperate (with aseasonal rainfall) in the south-eastern Albany Thicket, to subtropical (with summer rainfall) in the north-eastern Savanna. In addition the western and southern Cape rivers are acidic, and those of the east neutral to alkaline [25]. This environmental heterogeneity is probably greater than would be found in the species' distribution in the rest of Africa, and if B. harrisoni did contain independent cryptic taxa, they are most likely to occur here. To contextualise the rest of Africa, specimens of $B$. harrisoni from Zambia and Malawi were included in the study.

At least ten nymphs of $B$. harrisoni were collected from each of 19 rivers spread across South Africa and one river in each of Zambia and Malawi (Figure 1, see Additional file 1: Table S1) and preserved in 96\% ethanol. Two or three specimens from each river were used for molecular analysis, while the remaining specimens were kept for future morphological study. Nymphs of $B$. 


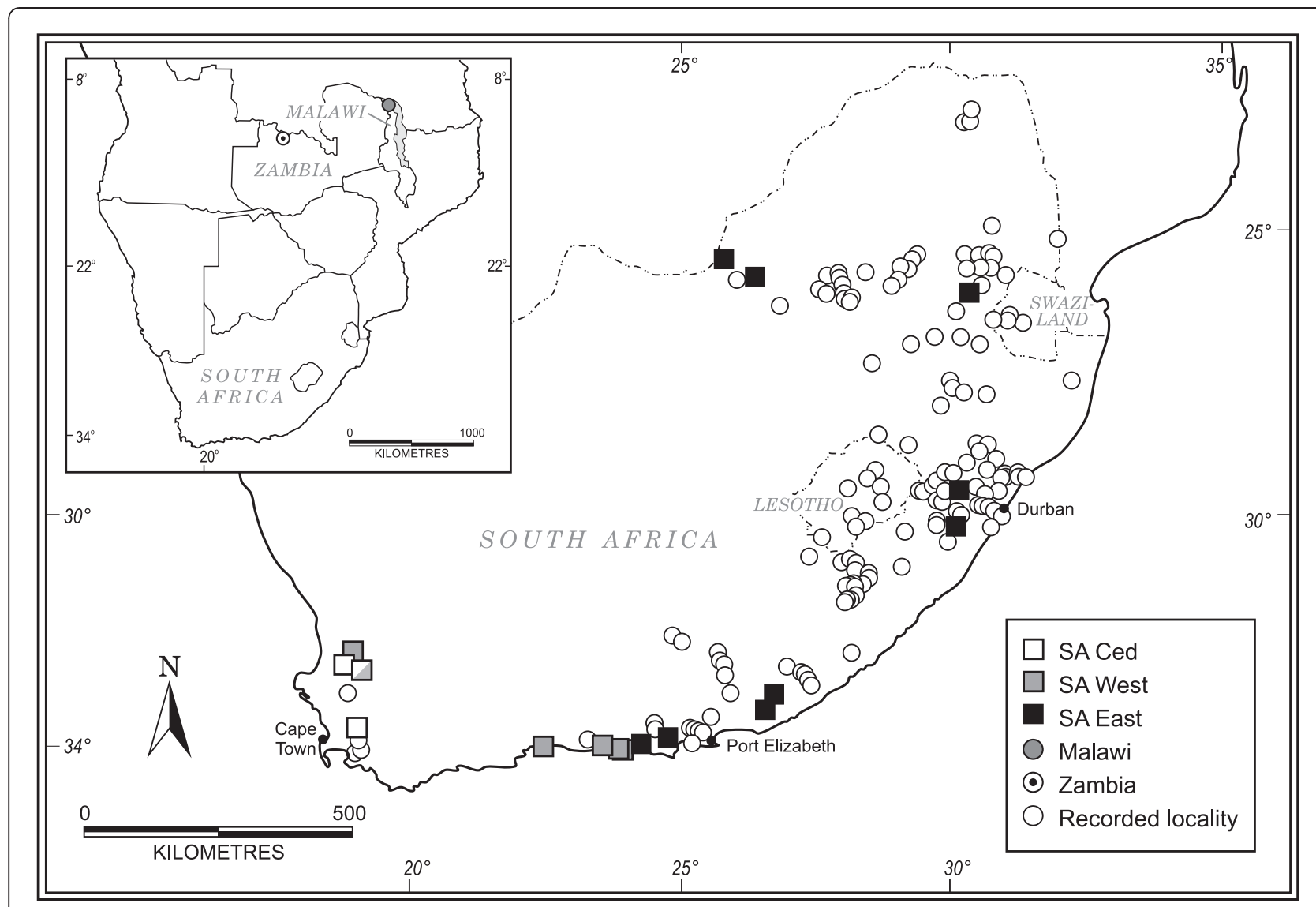

Figure 1 Map of recorded and sampled localities. Recorded localities of $B$. harrisoni and the location of sampled sites corresponding to the major lineages of B. harrisoni in Southern Africa. Data obtained from the Albany Museum database.

rhodani were provided by Dr Jean-Luc Gattolliat (Museum of Zoology, Switzerland) to serve as an outgroup. Vouchers of samples extracted for DNA (heads and the first pair of legs, or whole exoskeletons) are housed at the Albany Museum, Grahamstown (AMGS).

\section{Molecular data}

DNA was extracted either from the entire abdomen using the Chelex ${ }^{\circledR} 100$ extraction protocol [26] or by internal body digestion using the Invisorb extraction kit (Invitek).

Partial segments of four gene regions were amplified and sequenced, two mitochondrial (cytochrome c oxidase subunit I [COI] and small subunit ribosomal 165 rDNA [16S]) and two nuclear (elongation factor 1 alpha $[E F 1 \alpha]$ and phosphoenol pyruvate carboxykinase [PEPCK]). The primers used for both the PCR and sequencing reactions were as follows: COI was amplified using C1-N-2568 [27] and C1-J-1718 [28]; $16 \mathrm{~S}$ was amplified using $16 \mathrm{Sar}$ and $16 \mathrm{Sbr}$ [29]; EF1 $\alpha$ was amplified using DV-EF-F1 (5' - CAGGAYG TATACAAAATTGGTGG -3') (Vanderpool, unpublished) and DALL (5' - CTACACACATTGGTTTGCTGGG -3') designed for this study; PEPCK was amplified using
pepFb12 (5'- GGAACTTCAAACAGCACCAAT -3') and pepRb45 (5' - ACCTTGTGTTCTGCAGCT -3') (modified by Vuataz, from [30]). All PCR reactions were performed in a $50 \mu \mathrm{l}$ volume using the following thermal cycling profile: initial denaturation of $94^{\circ} \mathrm{C}$ for $5 \mathrm{~min}$, followed by 35-40 cycles of denaturation at $94^{\circ} \mathrm{C}$ for 30 s, primer annealing at $48^{\circ} \mathrm{C}(\mathrm{COI}$ and $16 S), 53^{\circ} \mathrm{C}(E F 1 \alpha)$ or $52^{\circ} \mathrm{C}$ (PEPCK) for 30s, elongation at $72^{\circ} \mathrm{C}$ for $1 \mathrm{~min} 30 \mathrm{~s}$; followed by a final extension period of $72^{\circ} \mathrm{C}$ for $10 \mathrm{~min}$. PCR products were cleaned using the Wizard ${ }^{\circledR}$ SV (Promega Corp.) and Invisorb PCRapace (Invitek) quick purification kits.

Cycle sequencing of the cleaned PCR product was carried out in both directions for each gene region using the flanking PCR primers and the ABI Big Dye Sequencing kit v.3.1, according to the manufacturer's instructions. Sequence trace files were generated using an ABI 3100 genetic analyser situated at Rhodes University. Trace files were checked and edited using GeneStudio v.2 (GeneStudio, Inc). Sequences were initially aligned using the ClustalW algorithm in MEGA v.4 [31] using the default parameters and then refined manually. Gaps in the $16 S$ alignment were treated as missing data and there were no introns in the PEPCK or EF1 $\alpha$ alignments. 
Sequences are available through GenBank [GenBank: HM636930-HM637101] (see Additional file 1: Table S1).

\section{Phylogenetic analyses}

To test whether the data from each dataset (corresponding to each gene region) could be combined into a single data set, pairwise Incongruence Length Difference (partition homogeneity) tests [32] were conducted in PAUP* v.4.0b10 [33], using 1000 replicates. Each gene was tested for substitution saturation using plots of transitions and transversions against F84 distance in DAMBE v4.5 [34]. Analyses were then conducted using Maximum Parsimony (MP) and Bayesian Inference (BI) for each dataset independently and the combined molecular data.

Each gene dataset was tested for the most appropriate model of sequence evolution using the AIC test [35] as implemented in MrModeltest v.2.2 [36] using MrMTgui (available from http://genedrift.org/software/mrmtgui.html).

Bayesian Inference analyses were conducted using MrBayes v.3.1.2 [37] for each of the datasets. Each BI analysis comprised two independent runs each of ten million generations. Random starting trees with four chains (one cold, three hot) were used with trees sampled every 1000 generations. All model parameters except branch length and topology were unlinked across partitions and among-partition rate variation was accommodated following Marshall et al. [38]. Stationarity was assessed using the Potential Scale Reduction Factor data and plots of likelihood scores, tree length and average standard deviation of split frequencies against the number of generations. The first 1000 trees sampled (10\%) were discarded from each run as burn-in. The majority rule consensus Bayesian topology and posterior probability values were then computed from the remaining sampled trees. For the combined analysis the effect of partitioning the data by gene was estimated using pairwise comparison of Bayes Factors (sensu) $[39,40]$ with $2 \operatorname{lnBF}_{A-B} \geq 10$ indicative of strong support for partitioning strategy A vs. B, following Kass and Raftery [41]. Although popular, the harmonic mean (HM) estimate of the marginal likelihood as reported by MrBayes is a biased estimator of the marginal likelihood [42] with a large and unpredictable variance [43]. These properties render the HM inappropriate for Bayes Factor comparisons, instead the more recent stepping stone (SS) method is recommended [42,44]. Following analysis in MrBayes the marginal likelihood of the trees resulting from the two partitioning strategies were re-estimated using the generalized stepping stone (SS) method [44] as implemented in Phycas 1.2.0 [www.phycas.org] using 30 $\beta$-values with 1000 cycles per $\beta$.

Parsimony analyses were performed using the heuristic search option in PAUP* version 4.0b10 [33]. A simple search with TBR (Tree Bisection and Reconnection) branch-swapping was used to find the approximate length of the shortest trees. This was followed by a random input analysis using 1000 repetitions and TBR branch-swapping, keeping all trees equal to or shorter than the shortest tree found in the simple search. This process was repeated until no shorter trees were found. All of the shortest trees were retained and used to compute the strict consensus tree. Nodal support was investigated using 100 bootstrap pseudoreplicates [45] with MAXTREES set to 10000 , TBR branch-swapping and simple stepwise addition.

To estimate the contribution of each dataset to the overall support of each node, partitioned Bremer support (PBS) values [46-49] were calculated using TreeRot v.3 [50] and PAUP* using only the parsimony informative characters for each dataset and 1000 random addition replicates. As only the major lineages were of interest, the PBS analysis used a reduced dataset comprising only individuals from each clade represented with the complete molecular dataset.

Both mean within- and between-clade distances were estimated from the COI and PEPCK data using the Maximum Composite Likelihood model in MEGA 4 [31]. In addition, the contribution of Isolation by Distance (IBD) was estimated using the most informative gene data set $(C O I)$ in GenAlEx 6.1 [51] with 999 permutations using the Mantel test in GenAlEx 6.1, initially for the group as a whole and subsequently for each clade individually, excluding the Zambian and Malawian clades that originated from one site each, preventing analysis.

\section{Dating analysis}

As no fossils were available, a tentative dating analysis used minimum (1.5\% per MY; [52]) and maximum (3.5\% per MY; [53]) reported values for COI substitution rates of insects calibrated within the last $10 \mathrm{MY}$. Divergence times were estimated using BEAST v1.6.1 [54] as follows. Data were partitioned by gene (PEPCK, 16S, COI) and the model parameters selected by MrModeltest for each partition (Table 1) were incorporated into each analysis. Each analysis comprised four independent runs of 50 million generations, with a UPGMA (Unweighted Pair Group Method with Arithmetic Mean) starting tree under the assumptions of an uncorrelated log-normal (UCLN) relaxed clock. The PEPCK and $16 S$ substitution rates were estimated relative to the $\mathrm{COI}$ rate $(\mathrm{COI}$ rate set at 0.0075 or 0.0177 substitutions per site per MY) in BEAST. Each analysis was run under either a Coalescent (Constant Size), Yule, or Birth-Death prior to ascertain the affect of these tree priors on the resulting divergence estimates. Run statistics including the effective sample size for each parameter were examined in Tracer v1.5 [55] and convergent independent runs for each analyses 
Table 1 Data characteristics and analysis summaries

\begin{tabular}{|c|c|c|c|c|c|c|c|c|c|c|c|}
\hline \multirow[b]{2}{*}{ Dataset } & \multirow[b]{2}{*}{ ntax } & \multicolumn{4}{|c|}{ Characters } & \multicolumn{4}{|c|}{ Parsimony analysis } & \multicolumn{2}{|c|}{ Bayesian analysis } \\
\hline & & bp & \# Var & $\# \mathbf{P i}$ & $\% \mathbf{P i}$ & \# trees & Score & $\mathbf{C l}$ & $\mathbf{R I}$ & Model (AIC) & InL \\
\hline PEPCK & 52 & 357 & 58 & 33 & 9.2 & 10000 & 49 & 0.776 & 0.969 & $K 80+G$ & $-1063.23(1 P)$ \\
\hline EF1a & 21 & 458 & 33 & 14 & 3.1 & 5 & 18 & 0.833 & 0.957 & $\mathrm{GTR}+\mathrm{I}$ & $-913.51(1 P)$ \\
\hline 165 & 50 & 502 & 71 & 65 & 13.0 & 10000 & 104 & 0.779 & 0.965 & $\mathrm{GTR}+\mathrm{I}$ & $-1393.33(1 P)$ \\
\hline $\mathrm{COl}$ & 50 & 618 & 224 & 191 & 31.0 & 15 & 424 & 0.642 & 0.936 & $\mathrm{GTR}+\mathrm{I}+\mathrm{G}$ & $-3016.22(1 P)$ \\
\hline$P E P C K+165+C O I$ & 67 & 1477 & 353 & 289 & 20.0 & 10000 & 586 & 0.667 & 0.943 & $G T R+I+G$ & $\begin{array}{l}-5724.33^{*}(1 P) \\
-5315.31^{*}(3 P)\end{array}$ \\
\hline
\end{tabular}

The number of specimens with sequence data (ntax), number of variable (\# Var), parsimony informative (\# Pi), percent parsimony informative (\% Pi) and total number of base pairs (bp) is reported. The parsimony search summary comprises the number of trees retained (\# trees), tree length (score), Consistence Index (Cl) and Retention Index (RI). The Bayesian analysis summary comprises the model selected by MrModeltest, the harmonic mean of the estimated marginal likelihoods and the partitioning strategy indicated in brackets; an asterisk indicates the value is the re-estimated marginal likelihood using the generalized stepping stone model.

were then combined in Log Combiner 1.6.1 (part of the BEAST package) with a final burn-in (10\%) of the trees. Node ages and the corresponding confidence intervals were then summarised using a Maximum Clade Credibility (MCC) tree in TreeAnnotator v1.6.1 (part of the BEAST package). These trees and corresponding node ages were viewed using FigTree v1.3.1 (part of the BEAST package).

\section{Species delimitation}

Species boundaries were explored using changes in branching rates following Pons et al [56]. Both single and multiple thresholds, general mixed Yule-coalescent (GMYC) models were applied to each gene in isolation and to the combined data. After removing the outgroup specimens and all duplicate haplotypes, each chronogram was estimated using BEAST under the appropriate gene-specific model parameters (Table 1), with a relaxed uncorrelated log-normal (UCLN) clock, the mean substitution rate fixed at 1 and branch lengths estimated using a Coalescent (Constant Size) prior. Analyses were run for 50 million generations. Following the BEAST analyses the Maximum Clade Credibility chronograms were analysed using the SPLITS (available from http://r-forge. r-project.org/projects/splits) and APE [57] packages in the $\mathrm{R}$ statistical environment ( $\mathrm{R}$ Development Core Team, 2011). A log-likelihood ratio test was then used to assess the significance of the estimated shift in branching rates for both the single and multiple threshold models in each analysis.

\section{Results}

\section{Data characteristics}

The combined molecular data consisted of 67 specimens and 1935 nucleotides $(16 S=502$ bp; $P E P C K=357$ bp; $C O I=618 \mathrm{bp} ; E F 1 \alpha=458 \mathrm{bp)}$ obtained from specimens from 22 rivers (see Additional file 1: Table S1; Figure 1) including outgroups. Certain sample sequences were successfully amplified for some genes and not others and are therefore absent in certain gene analyses (see Additional file 1: Table S1). Of the four genes, COI showed the most variation and EF1 $\alpha$ the least (Table 1). Individual plots of transitions and transversions against F84 distance for the ingroup samples showed no signs of saturated substitution within the four datasets (data not shown).

\section{Phylogenetic analyses}

The results of the Parsimony and Bayesian analyses are summarised in Table 1. Pairwise ILD tests showed that three of the four datasets were not significantly incongruent, with the exception of $E F 1 \alpha$ which was significantly incongruent from the other three genes (Table 2). Comparison of the two partitioning strategies in the combined Bayesian analyses showed no change in topology but an improvement in the support of a single node (Figure 2: the posterior probability of node 3 improved from 0.62 [single partition] to 0.97 [three partitions]). Comparison of the marginal likelihoods estimated using the generalized stepping stone (SS) method suggested that partitioning data by gene provided a much better $\ln$-likelihood value $\left(2 \operatorname{lnBF}_{1-3}=818.04\right)$ than not partitioning the data for each gene (Table 1), and thus the results of the Bayesian analysis partitioning the data by gene (three partitions) are shown (Figure 2).

Five clades were found, consisting of samples collected from the Cederberg mountains and the Breede River district, which is a winter rainfall region of South Africa

Table 2 Pairwise Incongruence Length Difference (ILD)

\begin{tabular}{llll}
\hline Partition & EF1a & PEPCK & 16S \\
\hline EF1a & - & & \\
PEPCK & $\mathbf{0 . 0 1}$ & - & \\
165 & $\mathbf{0 . 0 1}$ & 0.61 & - \\
COI & $\mathbf{0 . 0 1}$ & 0.20 & 0.74
\end{tabular}

ILD test probability values for the four data partitions generated using 1000 replicates. Statistically significant values are emphasised in bold. 


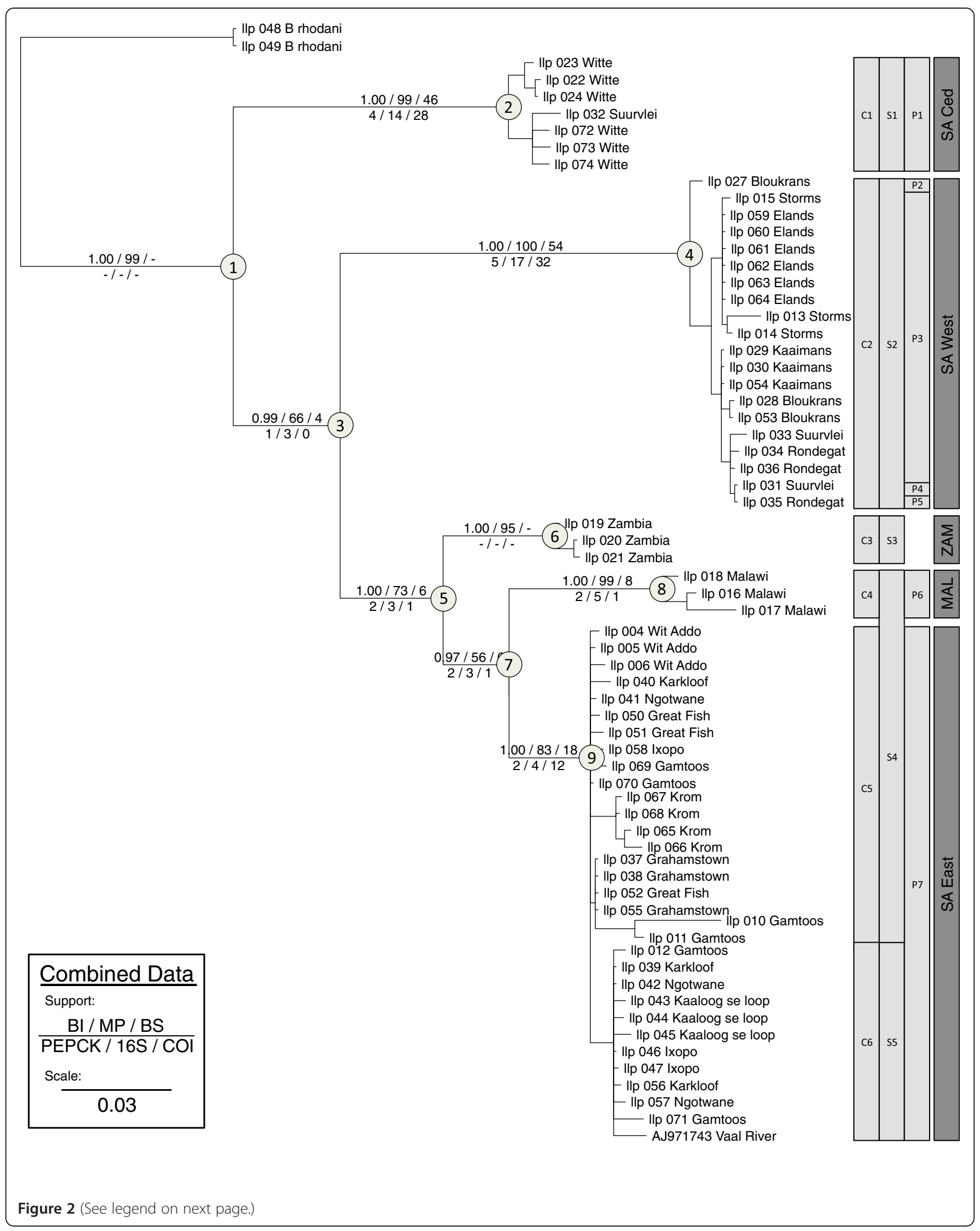


(See figure on previous page.)

Figure 2 Combined Bayesian Inference with GMYC. Bayesian Inference phylogram of combined molecular data (excluding EFTa data) with support for major nodes shown above (Bayesian posterior probability / Parsimony bootstrap / Bremer support) and below (partitioned Bremer support: PEPCK / $16 \mathrm{~S}$ / COI) each branch. The columns to the right of the tree indicate species boundaries identified by the GMYC likelihood analyses for the COI (clades: C1-C6), 165 (clades: S1-S5) and PEPCK (clades: P1-P7) partitions respectively. The fourth (dark grey) column shows five well supported monophyletic consensus groups identified by the GMYC likelihood analyses of the combined data (PEPCK + 16S + CO), representing putative phylogenetic species further discussed in this study. Node numbers (circled) correspond to date estimates reported in Tables 4 \& 5 and Additional file 2: Figure S1.

hereafter termed "SA Ced"; the entire winter rainfall region of South Africa, Cederberg inclusive, hereafter termed "SA West"; and the eastern summer rainfall region of southern Africa, corresponding to samples from South Africa "SA East"; Malawi, "MAL"; and Zambia, "ZAM". The arrangement of the various clades differed depending on the data analysed.

Analysis of the $16 S$ data resulted in a basal polytomy (Figure 3a). Two clades (SA Ced and SA West) were recovered as monophyletic; samples from eastern rivers were recovered as two paraphyletic clades (SA East + MAL) and (ZAM). Three clades (SA Ced, SA West and
(SA East + MAL)) received good support (MP: $\geq 82$; BI: $\geq 0.94$ ) while the clade from Zambia (ZAM) received moderate support (MP: 82; BI: 0.81). Analysis of the PEPCK data (Figure 3b) resulted in three clades (SA Ced, SA West and (SA East + MAL)), with two (SA Ced and SA West) receiving good support (MP: $\geq 90$; BI: 1.00). Within the eastern lineage the SA East samples formed a well-supported clade (MP: $\geq 90$; BI: $\geq 0.98$ ), whereas the samples from Malawi (MAL) were monophyletic but only moderately supported (MP: 63; BI: 0.87) and the samples from Zambia (ZAM) did not amplify for this gene. Analysis of the COI data (Figure 3c) indicated five clades (SA Ced, SA West, SA (a) $16 \mathrm{~S}$

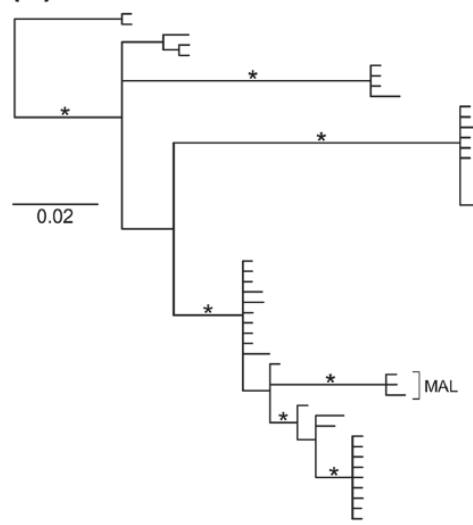

(c) $\mathrm{COI}$

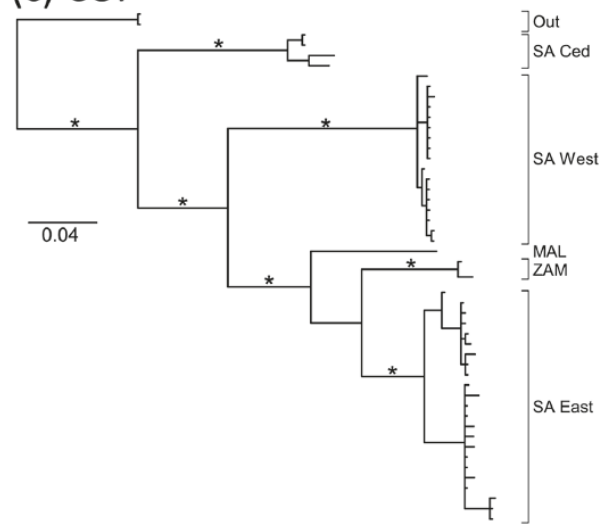

(b) PEPCK

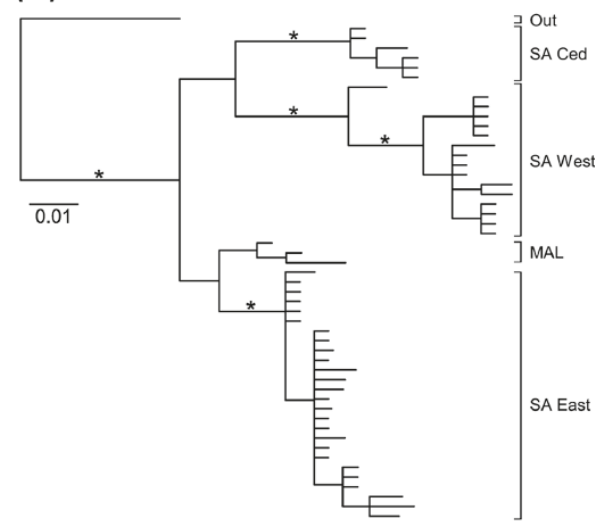

(d) EF1 $\alpha$

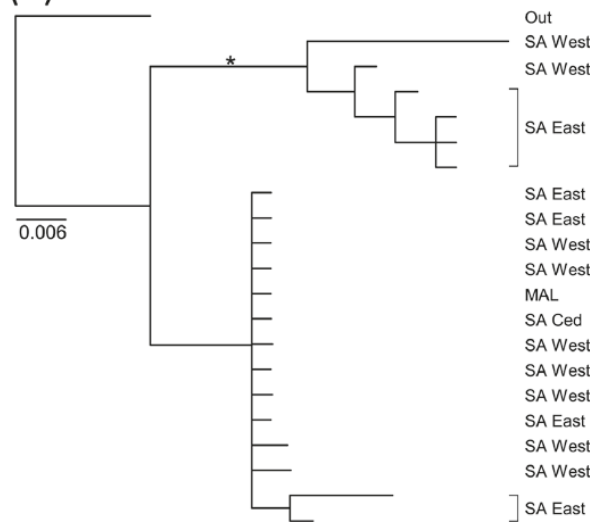

Figure 3 Bayesian Inference Phylograms. Bayesian Inference phylograms of each of the four different datasets corresponding to each individual gene: (a) 165 (b) PEPCK (c) COI (d) EFla. Posterior probability support ( $p>0.95)$ is indicated using an asterisk above the corresponding branch. 
East, MAL and ZAM), each with good support (MP: $\geq 99$; BI: 1.00). The trees recovered from analyses of the $E F 1 \alpha$ data (Figure 3d) were poorly supported and incongruent with the trees produced from the other genes, both when analysed separately (Figure 3a-c) and when combined in a total evidence analysis (Figure 2). Specimens that were represented in distinct geographic clades within the $16 S$, PEPCK and COI analyses were indistinguishable in the $E F 1 \alpha$ analysis (Figure $3 \mathrm{~d}$ ).

Considering the limited phylogenetic information provided by the EF1 $\alpha$ data (Table 1) and their significant incongruence with all other sampled datasets (Table 2), the EF1 $\alpha$ gene was excluded from the combined analysis (Figure 2). The MP and BI analyses of the combined remaining molecular data (comprising 16S, PEPCK and COI datasets) recovered five monophyletic lineages (SA Ced, SA West, SA East, MAL and ZAM). Three lineages (SA Ced, SA West and a combined "eastern" clade comprising (SA East + MAL + ZAM)) received good support (MP: $\geq 73$; BI: 1.00). Within the eastern clade the Zambian (ZAM) lineage was recovered as sister to the combined Malawian (MAL) and South African (SA East) lineages, which received moderate support (MP: 56; BI: 0.97). In addition the sister relationship of ((SA East + MAL + ZAM) and SA West) received moderate support (MP: 66; BI: 0.99). The PBS analysis indicated little conflict between the three (16S, PEPCK and COI) datasets, with very good support for each clade (combined $P B S \geq 8$ ) but only moderate support for the between-clade relationships (combined PBS $\leq 6$ ).

The within-clade distance estimated using the Maximum Composite Likelihood model was comparatively low $(C O I$ : mean $=1.8 \%$, range $=0.5-3.0 \%$; PEPCK: mean $=0.7 \%$, range $=0.2-0.9 \%$, whereas the betweenclade distance was an order of magnitude greater (COI: $\quad$ mean $=17.6 \%$, range $=11.6-22.5 \%$; PEPCK: mean $=4.4 \%$, range $=2.4-5.7 \%$ ) and comparable to the distance between the ingroup and outgroup taxa (COI: mean $=22.4 \%$; range $=21.1-23.6 \% ;$ PEPCK: mean $=7.5 \%$, range $=6.7-9.6 \%)$.

Isolation by Distance (IBD) analyses of the samples as a whole showed a small but significant effect of IBD $\left(\mathrm{R}^{2}=0.084 ; p=0.001\right)$. The contribution of IBD was minimal within each individual clade (Table 3 ).

\section{Dating analysis}

The topology of the various BEAST dating analyses (data not shown) agreed in general with the MrBayes analysis (Figure 2), with two exceptions: the analysis under a Yule prior and a COI substitution rate of $1.5 \%$ per $\mathrm{MY}$ (Table 4) and the analysis under a Birth-Death prior and a COI substitution rate of $3.5 \%$ per MY (Table 5), both of which did not recover a monophyletic clade comprising (SA East + MAL + ZAM + SA West: Figure 2, node 3)
Table 3 Isolation by Distance (IBD)

\begin{tabular}{lll}
\hline Clade & $\mathbf{R}^{\mathbf{2}}$ & $\boldsymbol{P}$ \\
\hline INGROUP & 0.084 & $\mathbf{0 . 0 0 1}$ \\
SA Ced & 0.338 & 0.077 \\
SA West & 0.064 & $\mathbf{0 . 0 2 2}$ \\
SA East & 0.132 & $\mathbf{0 . 0 0 1}$ \\
SA East + MAL + ZAM & 0.717 & $\mathbf{0 . 0 0 1}$
\end{tabular}

The contribution of Isolation by Distance $\left(\mathrm{R}^{2}\right)$ and corresponding probability values $(p)$ for each clade analysed using the $\mathrm{COI}$ gene. Statistically significant values are emphasised in bold.

due to a weakly supported clade comprising (SA West + SA Ced). Unsurprisingly divergence estimates were affected by both the tree prior and the substitution rate used (Tables $4 \&$ 5; Additional file 2: Figure S1). The fast substitution rate $(3.5 \%$ per $\mathrm{MY})$ resulted in divergence estimates which were approximately half those estimated using the slow substitution rate (1.5\% per MY) across the whole range of estimates. The effect of tree prior was relatively minor for the within clade estimates (Tables 4 \& 5; Additional file 2: Figure S1) but the between clade divergence estimates were strongly affected by the tree prior with a Yule prior favouring divergence estimates that were approximately half of those estimated using the Coalescent and Birth-Death priors (Tables 4 \& 5; Additional file 2: Figure S1). Comparisons of the individual BEAST runs using the Bayes Factor calculator in Tracer with 1000 bootstrap replicates showed that a Yule prior (3.5\% Ln $=-5294.406 ; 1.5 \% \operatorname{Ln}=-5295.392)$ was favoured over both the Coalescent prior $(3.5 \%$ Ln $=-5295.698 ; 1.5 \% \operatorname{Ln}=-5296.326)$ and Birth-Death prior $(3.5 \% \operatorname{Ln}=-5296.363 ; 1.5 \% \operatorname{Ln}=-5295.95)$, although this support was only marginal $\left(2 \operatorname{lnBF}_{\mathrm{A}-\mathrm{B}} \leq 4\right.$ in all pairwise comparisons).

Within each of the lineages the mean time to most recent common ancestor (TMRCA) ranged from the youngest: $0.5-0.7$ mya (MAL) to the oldest: 1.5-1.7 mya (SA East) using the faster rate (Table 5) or 1.1-1.6 mya (MAL) to 3.4-3.9 (SA East) using the slower rate (Table 4). The ingroup taxa are estimated to share a common ancestor in the mid- to late Miocene at least 5.2 mya (fast rate, Yule prior)-24.6 mya (slow rate, Birth-Death prior). The most recent cladogenesis between major lineages occurred at least 2.4 mya (fast rate, Yule prior)-8.9 mya (slow rate, Birth-Death prior) between the SA East and MAL lineages (Table 4).

\section{Species delimitation}

The results of the individual GMYC analyses are summarised in Table 6. In all cases the multiple-threshold model was not significantly different from the single model and was rejected in favour of the more conservative single threshold model. The COI data recovered six 
Table 4 TMRCA with substitution rate at $1.5 \%$ per My

\begin{tabular}{|c|c|c|c|c|c|c|c|}
\hline \multirow[b]{2}{*}{ Clade } & \multirow[b]{2}{*}{ Node } & \multicolumn{2}{|c|}{ Coalescent prior } & \multicolumn{2}{|l|}{ Yule prior } & \multicolumn{2}{|c|}{ Birth-Death prior } \\
\hline & & TMCRA (mya) & 95\% HPD & TMCRA (mya) & 95\% HPD & TMCRA (mya) & 95\% HPD \\
\hline MAL & 8 & 1.27 & $(0.19-2.86)$ & 1.63 & $(0.29-3.36)$ & 1.14 & $(0.15-2.58)$ \\
\hline ZAM & 6 & 1.55 & $(0.19-3.63)$ & 1.88 & $(0.24-4.16)$ & 1.45 & $(0.19-3.38)$ \\
\hline SA Ced & 2 & 2.19 & $(0.65-4.23)$ & 2.11 & $(0.65-3.94)$ & 1.99 & $(0.60-3.79)$ \\
\hline SA West & 4 & 3.04 & $(1.04-5.65)$ & 3.54 & $(1.35-6.19)$ & 2.71 & $(0.93-5.12)$ \\
\hline SA East & 9 & 3.92 & $(1.97-6.30)$ & 3.45 & $(1.66-5.73)$ & 3.84 & $(1.80-6.29)$ \\
\hline (SA East + MAL) & 7 & 8.19 & $(3.91-13.09)$ & 5.75 & $(2.81-9.60)$ & 8.85 & $(3.92-14.72)$ \\
\hline (SA East + MAL + ZAM) & 5 & 12.74 & $(5.96-20.13)$ & 7.74 & $(3.68-12.71)$ & 13.92 & $(6.30-22.81)$ \\
\hline (SA East + MAL + ZAM + SA West) & 3 & 18.80 & $(9.41-29.73)$ & - & - & 20.09 & $(9.41-32.88)$ \\
\hline$($ SA East + MAL + ZAM + SA West + SA Ced $)$ & 1 & 24.23 & $(12.68-38.46)$ & 11.49 & $(5.64-18.63)$ & 24.63 & $(11.41-39.94)$ \\
\hline
\end{tabular}

Mean and 95\% HPD estimates of the time to most recent common ancestor (TMRCA) estimated using a COI substitution rate of $1.5 \%$ per My in BEAST. Node numbers correspond to those in Figure 2; "-" represents node present in Figure 2 but absent in BEAST analysis. Clades shown in ascending order of age of MRCA.

ML entities (Figure 2, C1-C6) the $16 \mathrm{~S}$ data recovered five ML entities (Figure 2, S1-S5) and the PEPCK data recovered seven $\mathrm{ML}$ entities (Figure 2, P1-P6), but none of these outcomes were significantly different from the null model of a single species. However, the combined $C O I+16 S+P E P C K$ data recovered six ML entities, which was significantly different from the null model of a single species $(p=0.04)$. Five of these entities correspond to monophyletic, well supported clades (Figure 2).

\section{Discussion}

The use of multiple molecular data sources enables the comparison of the evolutionary history of each gene and potentially more accurate estimation of the evolutionary history of the focal organisms (e.g. [58]). In the case of $B$. harrisoni, the combination of sequence data from four genes identified which genes are useful for identifying lineages with this level of divergence (e.g. COI and $P E P C K)$ and which genes should be avoided in future studies (e.g. $16 S$ and $E F 1 \alpha$ ). Furthermore, the combined sequence data resulted in a more resolved and well-supported phylogenetic hypothesis than when each of the individual datasets were analysed alone (Figures 2 and 3). This result is highlighted by the partitioned Bremer support values which show little incongruence (i.e. absence of negative and positive Bremer support values on a particular node) and, when the Bremer values are combined, provide moderate to strong support for the relationships of the major lineages (Figure 2), suggesting that singlegene datasets should be supplemented wherever possible $[59,60]$. Thus, the results presented here provide substantiate the approach of previous studies of the genus Baetis $[15,16]$ and suggest means of refining them.

\section{Gene tree incongruence}

The results produced from the $16 \mathrm{~S}$ gene were incongruent (but not significantly so) with the $C O I$ and nuclear (PEPCK) results, due to the recovery of a paraphyletic clade (SA East + MAL) (Table 2, Figure 3a). Possible explanations for incongruence include a lack of appropriately

Table 5 TMRCA with substitution rate at $3.5 \%$ per My

\begin{tabular}{llllllll}
\hline & \multicolumn{3}{c}{ Coalescent prior } & \multicolumn{3}{c}{ Yule prior } & \multicolumn{3}{c}{ Birth-Death prior } \\
\hline Clade & Node & TMCRA (mya) & 95\% HPD & TMCRA (mya) & 95\% HPD & TMCRA (mya) & 95\% HPD \\
\hline MAL & 8 & 0.59 & $(0.08-1.30)$ & 0.70 & $(0.13-1.55)$ & 0.54 & $(0.09-1.20)$ \\
ZAM & 6 & 0.71 & $(0.08-1.68)$ & 0.85 & $(0.10-1.92)$ & 0.64 & $(0.06-1.52)$ \\
SA Ced & 2 & 0.96 & $(0.25-1.87)$ & 0.94 & $(0.28-1.77)$ & 0.89 & $(0.26-1.76)$ \\
SA West & 4 & 1.41 & $(0.48-2.64)$ & 1.60 & $(0.62-2.86)$ & 1.29 & $(0.46-2.41)$ \\
SA East & 9 & 1.73 & $(0.80-2.92)$ & 1.54 & $(0.72-2.59)$ & 1.71 & $(0.81-2.83)$ \\
(SA East + MAL) & 7 & 3.64 & $(1.71-6.08)$ & 2.40 & $(1.25-4.29)$ & 3.96 & $(1.69-6.65)$ \\
(SA East + MAL + ZAM) & 5 & 5.67 & $(2.50-9.48)$ & 3.46 & $(1.66-5.75)$ & 6.24 & $(2.71-10.52)$ \\
(SA East + MAL + ZAM + SA West) & 3 & 8.16 & $(3.85-13.51)$ & 4.33 & $(2.20-6.95)$ & - & \\
(SA East + MAL + ZAM + SA West + SA Ced) & 1 & 10.42 & $(4.90-17.33)$ & 5.15 & $(2.66-8.51)$ & 13.23 & $(5.45-22.47)$ \\
\hline
\end{tabular}

Mean and 95\% HPD estimates of the time to most recent common ancestor (TMRCA) estimated using a COI substitution rate of 3.5\% per My in BEAST. Node numbers correspond to those in Figure 2; "-" represents node present in Figure 2 but absent in BEAST analysis. Clades shown in ascending order of age of MRCA. 
Table 6 Summary of GMYC

\begin{tabular}{|c|c|c|c|c|c|c|c|c|c|c|c|c|}
\hline \multirow[b]{2}{*}{ Dataset } & \multirow[b]{2}{*}{ H/G } & \multirow[b]{2}{*}{ Ln (null) } & \multicolumn{5}{|c|}{ Single threshold } & \multicolumn{5}{|c|}{ Multiple threshold } \\
\hline & & & Ln (GMYC) & LR & $p$ & ML entities & $\mathrm{Cl}$ & Ln (GMYC) & LR & $p$ & ML entities & $\mathrm{Cl}$ \\
\hline $\mathrm{COI}$ & 48 & 161.10 & 163.11 & 4.03 & 0.25 & 6 & $4-18$ & 163.72 & 1.50 & 0.68 & 9 & $5-13$ \\
\hline 165 & 48 & 106.58 & 108.46 & 3.75 & 0.29 & 5 & $1-15$ & 163.58 & 0.00 & 1.00 & 5 & $1-11$ \\
\hline PEPCK & 54 & 166.48 & 169.30 & 5.62 & 0.13 & 7 & $4-12$ & 169.49 & 0.38 & 0.94 & 6 & $4-15$ \\
\hline$P E P C K+16 S+C O I$ & 64 & 169.65 & 173.60 & 7.90 & 0.04 & 6 & $4-17$ & 173.84 & 0.48 & 0.92 & 7 & $6-32$ \\
\hline
\end{tabular}

Summary of the single and multiple threshold GMYC analyses, including the number of unique haplotypes/genotypes (H/G) in each dataset; the likelihood values estimated under the null (Coalescent) and GMYC (mixed Yule Coalescent) priors; the value used for the likelihood ratio test (LR) and its associated probability ( $p$ ), corresponding to a comparison between the single threshold and the null model, and the comparison between the multiple threshold and the single threshold models. The estimated number of Maximum Likelihood entities or "phylogenetic species" and the confidence interval (Cl) around these values are reported. Statistically significant values are emphasised in bold. ML entities correspond to clades labelled in Figure 2.

informative sites, substitution saturation, introgression, paralogy and/or incomplete lineage sorting. The $16 S$ gene is second to COI in its informative value (Table 1), although the data suffer from higher levels of homoplasy relative to the COI data (Table 1). Plots of transitions and transversions against genetic distance (not illustrated) showed that the $16 \mathrm{~S}$ data are not saturated. The mitochondrion is inherited as a single unit, thus the incongruence between the $16 S$ and COI data cannot be due to introgression, but may be due to incomplete lineage sorting of the $16 S$ gene.

The results produced from the EF1 $\alpha$ gene were significantly incongruent with both the mitochondrial (COI and $16 S)$ and nuclear (PEPCK) results. Possible explanations for the observed pattern are limited to introgression and/ or incomplete lineage sorting [61,62]. Although EF1 $\alpha$ is known to occur in two copies in some insects $[63,64]$, the lack of multiple PCR bands and the low between-clade divergence (0.03) estimated between the two clades would imply that only one copy has been amplified in this study. Although limited introgression is possible between a few samples in this study, it is not a viable explanation for the geographically distant samples, which were genetically indistinguishable (Figure 3d). Introgression in this case is also unlikely as there would have to have been multiple separate hybridisation events to result in the five distinct clades obtained from the COI and PEPCK data. Incomplete lineage sorting is the most likely explanation for the incongruence obtained between gene trees (Figure 3a-d), resulting from the random retention and extinction of alleles between species [61].

\section{Potential causes of lineage diversification}

Although the dispersal of mayflies is thought to be limited to nearby water bodies because they are weak fliers with short adult lifespans [3], it has been shown that long-distance dispersal is more prevalent than previously thought [65]. The lack of within-clade isolation by distance apparent in this study (when excluding geographically isolated samples from Malawi and Zambia) would suggest high levels of gene flow within the three lineages in South Africa.
The role of catchments and their corresponding watersheds in structuring the genetic history of organisms in southern Africa is well documented (e.g. redfin barbs: [66,67]; atyid shrimps: $[68,69]$; and cicadas: [70,71]), although the impact of different catchments on invertebrates with aquatic stages is varied, with evidence both for (e.g. [72-74]) and against (e.g. [75,76]) a catchment effect, dependent primarily on the dispersal ability of the organism [77]. Although the SA East lineage is not found in the same catchments as the SA West lineage, the combination of the widespread distribution of the SA East and SA West lineages over multiple primary catchments and the range overlap between the SA Ced and SA West lineages would suggest that there is little-to-no effect of catchments influencing population structuring.

The tentative dating analyses are based solely on two estimates of the COI substitution rate and thus are to be interpreted with caution, but they provide plausible first estimates for the group. The estimated time to most recent common ancestor (TMRCA) for each clade is not markedly affected by the tree prior (Tables 4 \& 5; Additional file 2: Figure S1), but the between-clade divergence estimates depend on the choice of tree prior with a Yule prior favouring younger estimates (Tables 4 \& 5; Additional file 2: Figure S1). In this case the combination of Bayes Factor support for the Yule prior and the proposed status of each clade as recently diverged but distinct phylogenetic species support the use of the between-species Yule prior over the within-species Coalescent prior and the more complex between-species with extinction Birth-Death prior.

Between clade divergence estimates under the Yule prior suggest that the major cladogenic events within the group took place during the Pliocene to mid-Miocene (Tables 4 \& 5; Additional file 2: Figure S1), a pattern in common with previous studies in the region, focussing on aquatic or semi-aquatic freshwater invertebrates [78-82] and fish [67], strongly suggesting that common processes (outlined below) may have been responsible.

The TMRCA estimated within each lineage ranged from the youngest (MAL: 0.5-0.7 mya) to the oldest (SA East: 1.5-1.7 mya) when using the faster COI 
substitution rate, suggesting population fragmentation within the Plio-Pleistocene. Within the Plio-Pleistocene, aridity and seasonality in southern Africa increased with the intensification of the Benguela current and the formation of the winter rainfall zone [83,84] and global climate fluctuations in response to Milankovitch oscillations [85] which resulted in glacial cycles throughout the Pleistocene. These glacial cycles, and the associated aridity linked to glacial periods [86], probably resulted in the repeated fragmentation and bottlenecking of Baetis populations within southern Africa and have been previously cited as a population isolating mechanism within the region $[71,87]$.

The lineages sampled in this study correspond to environmentally identified ( $\mathrm{pH}$-based) and summer versus winter rainfall variation. The SA Ced and SA West lineages comprise samples from streams that flow through acidic Table Mountain Sandstone geologies whereas the SA East, MAL and ZAM lineages comprise samples from streams with an alkaline $\mathrm{pH}$. The difference in the $\mathrm{pH}$ range of the rivers is primarily a result of the local geology $[14,25]$, so river $\mathrm{pH}$ is unlikely to have changed within the timeframe (Mio-Pliocene) required to result in the isolation of lineages. The response of many aquatic invertebrates to $\mathrm{pH}$ is well studied and it is known that the $\mathrm{pH}$ of a river affects its community composition $[88,89]$. Thus the lineages discussed in this study are each likely to have a restricted $\mathrm{pH}$ tolerance and this lineage-specific $\mathrm{pH}$ tolerance is the most likely mechanism for the continued genetic isolation between the parapatric SA West and SA East lineages of B. harrisoni. The Krom River (SA East, Figure 1, see Additional file 1: Table S1) and Elands River (SA West, Figure 1, see Additional file 1: Table S1) are approximately $30 \mathrm{~km}$ apart, yet the shift in geological composition results in a drastic change in $\mathrm{pH}$ over the short distance. The Elands River flows through areas of Table Mountain Sandstone (resulting in poorly-buffered acid waters) and the Krom River flows through Bokkeveld (mostly shale and sandstone composition which results in well-buffered neutral-to-alkaline waters) [90]. This mechanism requires experimental verification and cannot be invoked to explain the continued isolation between the sympatric SA West and SA Ced lineages.

\section{Taxonomic status of clades}

Although the South African material used in this study has been well sampled (Figure 1), the GMYC results must be interpreted with caution as there are large sampling gaps between South Africa and Malawi / Zambia and the GMYC model is sensitive to sampling strategies, which may result in artificial clustering due to a lack of intermediate haplotypes. Within South Africa the lineages are found both in sympatry (Figure 1: SA Ced and SA West) and parapatry (Figure 1: SA West and SA
East) and are estimated to share a common ancestor at least 2.4 mya (Tables 4 \& 5), suggesting five species under the phylogenetic species concept. The individual GMYC analyses resulted in the recognition of between 5 and 7 maximum likelihood (ML) entities, with the combined data favouring six ML entities. In analyses based on the COI, $16 S$ and the combined data, the SA East lineage was divided into two ML entities. As these two ML entities were not well supported monophyletic clades in all three (COI, $16 S$ and PEPCK) datasets, we have chosen a more conservative estimate of five monophyletic, well supported clades, corresponding to five phylogenetic species, here highlighted as: SA Ced, SA West, SA East, ZAM and MAL (Figure 2).

Furthermore the between-clade genetic distances estimated here are comparable to those found between distinct species both in this study (i.e. outgroup vs. ingroup) and in previous studies of Baetis species $[1,15,16]$, providing strong evidence for the recognition of five species corresponding to each of the lineages mentioned using the phylogenetic species concept. Although subtle morphological variations have been observed in B. harrisoni, these findings require a thorough morphological investigation to assess whether there are diagnostic morphological characters and observable physiological adaptations to acid or alkaline $\mathrm{pH}$ conditions which are consistent and congruent with the molecular lineages.

The Afrotropical region is undoubtedly under-collected and material collected is often insufficiently studied. This may explain the low diversity of African Baetis species despite the high generic diversity in the Afrotropical Baetidae [91]. Further sampling within Africa is needed to determine the geographical extent of each of the lineages within $B$. harrisoni sensu lato and to assess the diversity of the other Baetis species in the region (e.g. B. parvulus Crass, B. monikae Kopelke, B. permultus Kopelke and B. pseudogemellus Soldán).

\section{Conclusions}

In conclusion, consistent with studies of the Holarctic branch of the genus Baetis $[15,16]$, molecular markers have succeeded in revealing genetic variation that is indicative of cryptic species in southern African samples of $B$. harrisoni. Furthermore $C O I$ is cross-validated by the nuclear marker PEPCK as suitable for recognising these cryptic taxa. The $16 S$ gene shows indications of reduced phylogenetic information for the between-lineage relationships in this group while $E F 1 \alpha$ shows indications of incomplete lineage sorting, and is not recommended for identification, a conclusion which might be extended to other molecular studies of Baetis species (e.g. [15,16]). The tentative dating analyses indicate that historical and geographical processes within the mid-Miocene and Pliocene and continued isolation in response to water $\mathrm{pH}$ underlie the diversity in 
the B. harrisoni clade. Careful examination of morphology in the light of the clades recognised by this molecular study is warranted, and will aid in the resolution of the nomenclatural problems associated with this group. Finally these results have highlighted the need for accurate taxonomy in widely-used indicator species.

\section{Additional files}

Additonal file 1: Table S1. GenBank Accession numbers, samples and localities. Clade labels correspond to Figures 2 and 3. ('-' indicates failure to amplify; ${ }^{*}=$ sequence obtained from GenBank; EC = Eastern Cape; $\mathrm{KZN}=$ KwaZulu-Natal; LIM = Limpopo; MPU = Mpumalanga; NW= North West; RSA = South Africa; WC = Western Cape).

Additional file 2: Figure S1. Plot of the mean time to most recent common ancestor (TMRCA). Estimated using BEAST under differing tree priors and substitution rates. (A) mean $\mathrm{CO}$ substitution rate of 3.5\% per MY; (B) mean COI substitution rate of 1.5\% per MY. Error bars correspond to the estimated 95\% HPD. Dashed lines denote approximate boundaries of geologic epochs: Oli. Oligocene; Mio. Miocene; Pli. Pliocene; Ple. Pleistocene. Node numbering corresponds to Figure 2.

\section{Abbreviations}

Th. COI: Cytochrome c oxidase l; 16S: Small subunit ribosomal 16S rDNA; EFla: Elongation factor 1 alpha; PEPCK: Phosphoenolpyruvate carboxykinase; GMYC: General mixed yule-coalescent; IBD: Isolation By Distance; AMGS: Albany Museum, Grahamstown; MP: Maximum parsimony; BI: Bayesian Inference; TBR: Tree bisection and reconnection; PBS: Partitioned bremer support; MY: Million Years; UPGMA: Unweighted pair group method with arithmetic mean; UCLN: Uncorrelated Log-Normal; MCC: Maximum clade credibility; ntax: Number of specimens with sequence data; \# Var: Number of variable; \# Pi: Parsimony informative; \% Pi: Percent parsimony informative; Bp: Total number of base pairs; \# trees: Number of trees retained; score: Tree length; Cl: Consistence index; Rl: Retention index; TMRCA: Time to most recent common ancestor; LR: Likelihood ratio test; SA Ced: Samples collected from the Cederberg mountains and the Breede River district, which is a winter rainfall region; SA West: The entire winter rainfall region of South Africa, Cederberg inclusive; SA East: The eastern summer rainfall region of southern Africa, corresponding to samples from South Africa; MAL: Malawi; ZAM: Zambia.

\section{Competing interests}

The authors declare that they have no competing interests.

\section{Authors' contributions}

LLPdC collected specimens, acquired the molecular sequences genetic aligned sequences, drafted the manuscript and edited the final version. BWP conceived the phylogenetic analyses, and assisted with sequence alignment, interpretation of data and revision of the manuscript. HMB-J conceived the study, and provided specimens from outlying areas; HMB-J and MHV designed the study, coordinated and supervised the research group, and assisted the drafting and revision of the manuscript; MHV also acquired specimens and interpreted data. FCdM contributed material from Cederberg, Western and Eastern Cape rivers, and contributed ecological insights. NPB assisted with laboratory work and interpreted results. All authors contributed to manuscript writing and have read and approved the final manuscript.

\section{Acknowledgements}

The authors thank T.A. Bellingan, C. Chaussign, I.J. de Moor, J-L. Gattolliat, M. Graham, T. Hupin, S. Lowe, R.W. Palmer and H. Roux for donation of tissues; M. Monaghan for the use of DNA sequences; L. Vuataz for development of the PEPCK primers; the Pereira-da-Conceicoa family, M. Mundy and G. Keevey for assistance with field work, and S. Abraham for graphic designs. The Directorate of Museums and Heritage, Eastern Cape, are thanked for providing research facilities and encouraging this research. The financial support of the Department of Science and Technology, the National Research Foundation (NRF) of South Africa (Grants: 61263 to HBJ; 71139 to
BWP; 2053645 to NPB; 2069059 to MHV; 2069494 to FdM) and the Rhodes University Joint Research Council are greatly appreciated. BWP gratefully acknowledges a NRF Prestigious Scholarship and an Andrew Mellon Mentor Scholarship. Any opinion, findings and conclusions or recommendations expressed in this material are those of the authors and do not necessarily reflect the views of the National Research Foundation.

\section{Author details}

${ }^{1}$ Department of Zoology and Entomology, Rhodes University, P.O. Box 94, Grahamstown, 6140, South Africa. ${ }^{2}$ Department of Freshwater Invertebrates, Albany Museum, Somerset Street, Grahamstown, 6140, South Africa. ${ }^{3}$ Department of Ecology \& Evolutionary Biology, University of Connecticut, Storrs 06269 CT, USA. ${ }^{4}$ Molecular Ecology \& Systematics Group, Department of Botany, Rhodes University, P.O. Box 94, Grahamstown, 6140, South Africa.

Received: 14 October 2011 Accepted: 8 February 2012

Published: 29 February 2012

\section{References}

1. Ball SL, Hebert PDN, Burian SK, Webb JM: Biological identifications of mayflies (Ephemeroptera) using DNA barcodes. J North Am Benthol Soc 2005, 24:508-524.

2. Chutter FM: An empirical biotic index of the quality of water in South African streams and rivers. Water Res 1972, 6:19-30.

3. Brittain JE: Biology of Mayflies. Annu Rev Entomol 1982, 27:119-147.

4. Bauernfeind E, Moog O: Mayflies (Insecta: Ephemeroptera) and the assessment of ecological integrity: a methodological approach. Hydrobiologia 2000, 422:71-83.

5. Beketov MA: Different sensitivity of mayflies (Insecta, Ephemeroptera) to ammonia, nitrite and nitrate: linkage between experimental and observational data. Hydrobiologia 2004, 528:209-216.

6. Rutt GP, Weatherley NS, Ormerod SJ: Relationships between the physicochemistry and macroinvertebrates of british upland streams-the development of modeling and indicator systems for predicting fauna and detecting acidity. Freshw Biol 1990, 24:463-480

7. Bradley DC, Ormerod SJ: Long-term effects of catchment liming on invertebrates in upland streams. Freshw Biol 2002, 47:161-171.

8. Fialkowski W, Klonowska-Olejnik M, Smith BD, Rainbow PS: Mayfly larvae (Baetis rhodan and B. vernu) as biomonitors of trace metal pollution in streams of a catchment draining a zinc and lead mining area of Upper Silesia, Poland. Environ Pollut 2003, 121:253-267.

9. Palmer CG, Okeeffe $\mathrm{JH}$, Palmer AR: Are macroinvertebrate assemblages in the Buffalo River, Southern Africa, associated with particular biotopes. J North Am Benthol Soc 1991, 10:349-357.

10. Williams ML, Palmer CG, Gordon AK: Riverine macroinvertebrate responses to chlorine and chlorinated sewage effluents-Acute chlorine tolerances of Baetis harrison (Ephemeroptera) from two rivers in KwaZulu-Natal, South Africa. Water SA 2003, 29:483-488.

11. Dabrowski JM, Bollen A, Schulz R: Combined effects of discharge, turbidity, and pesticides on mayfly behavior: Experimental evaluation of spray-drift and runoff scenarios. Environ Toxicol Chem 2005, 24:1395-1402.

12. Gattolliat JL, Sartori M: What is Baetis rhodan (Pictet, 1843) (Insecta, Ephemeroptera, Baetidae)? Designation of a neotype and redescription of the species from its original area. Zootaxa 2008, 1957:69-80.

13. Lugo-Ortiz CR, de Moor FC, Barber-James HM: A taxonomic and ecological review of Pseudocloeon glaucu (Agnew) (Ephemeroptera: Baetidae). Afr Entomol 2000, 8:281-288.

14. Harrison AD, Agnew JD: The distribution of the invertebrates endemic to acid streams in the Western and Southern Cape Provinces. Ann Cape Prov Mus 1962, 2:273-291.

15. Williams HC, Ormerod SJ, Bruford MW: Molecular systematics and phylogeography of the cryptic species complex Baetis rhodan (Ephemeroptera, Baetidae). Mol Phylogenet Evol 2006, 40:370-382.

16. Ståhls G, Savolainen E: MtDNA COI barcodes reveal cryptic diversity in the Baetis vernu group (Ephemeroptera, Baetidae). Mol Phylogenet Evol 2008, 46:82-87.

17. Gattolliat JL, Monaghan MT: DNA-based association of adults and larvae in Baetidae (Ephemeroptera) with the description of a new genus Adnoptilu in Madagascar. J North Am Benthol Soc 2010, 29:1042-1057.

18. Sperling FAH: Butterfly molecular systematics: from species definitions to higher-level phylogenies. In Butterflies: ecology and evolution taking flight. 
Edited by Boggs CL, Watt WB, Ehrlich PR. Chicago: University of Chicago Press; 2003:431-458.

19. Funk DJ, Omland KE: Species-level paraphyly and polyphyly: frequency, causes, and consequences, with insights from animal mitochondrial DNA. Annu Rev Ecol Evol Syst 2003, 34:397-423.

20. Moritz C, Cicero C: DNA barcoding: promise and pitfalls. PLOS Biol 2004, 2:1529-1531.

21. Roe AD, Sperling FAH: Patterns of evolution of mitochondrial cytochrome c oxidase I and II DNA and implications for DNA barcoding. $\mathrm{Mol}$ Phylogenet Evol 2007, 44:325-345.

22. Tourle RA, Villet MH, Downie DA: Flies in the ointment: a morphological and molecular comparison of Lucilia cuprin and L. sericat (Diptera: Calliphoridae) in South Africa. Med Vet Entomol 2008, 23:6-14.

23. Moulton MJ, Song HJ, Whiting MF: Assessing the effects of primer specificity on eliminating numt coamplification in DNA barcoding: a case study from Orthoptera (Arthropoda: Insecta). Mol Ecol Resour 2010, 10:615-627.

24. Ballard JWO, Whitlock MC: The incomplete natural history of mitochondria. Mol Ecol 2004, 13:729-744.

25. Allanson BR, Hart RC, O'Keefe JH, Roberts RD: Inland waters of southern Africa, an ecological perspective. Dordrecht: Kluwer Academic Publishers; 1990.

26. Walsh PS, Metzger DA, Higuchi R: Chelex-100 as a medium for simple extraction of DAN for PCR-based typing from forensic material. Biotechniques 1991, 10:506-513.

27. Brady SG, Gadau J, Ward PS: Systematics of the ant genus Camponotu: a preliminary analysis using data from the mitochondrial gene cytochrome oxidase 1. In Hymenoptera: Evolution, Biodiversity, and Biological Control. Edited by Austin AD, Dowton M. Clayton: CSIRO Publishing; 2000:131-139.

28. Simon C, Frati F, Beckenbach A, Crespi B, Liu H, Flook P: Evolution, weighting, and phylogenetic utility of mitochondrial gene-sequences and a compilation of conserved polymerase chain-reaction primers. Ann Entomol Soc Am 1994, 87:651-701.

29. Palumbi SR, Martin A, Romano S, McMillan WO, Stice L, Grabowski G: A simple fool's quide to PCR. Honolulu: University of Hawaii Press; 1991.

30. Vuataz L, Sartori M, Wagner A, Monaghan MT: Toward a DNA taxonomy of alpine Rhithrogen (Ephemeroptera: Heptageniidae) using a mixed Yulecoalescent analysis of mitochondrial and nuclear DNA. PloS One 2011, 6:e19728. doi:10.1371/journal.pone.0019728.

31. Tamura K, Dudley J, Nei M, Kumar S: MEGA4: molecular evolutionary genetics analysis (MEGA) software version 4.0. Mol Biol Evol 2007, 24:1596-1599.

32. Farris JS, Kallersjo M, Kluge AG, Bult C: Testing significance of incongruence. Cladistics 1994, 10:315-319.

33. Swofford DL: PAUP* Phylogenetic Analysis Using Parsimony ( $^{*}$ and other methods), version 4. Sunderland, Massachusetts: Sinauer Associates; 2011.

34. Xia X, Xie Z: DAMBE: software package for data analysis in molecular biology and evolution. J Hered 2001, 92:371-373.

35. Akaike H: A new look at the statistical model identification. IEEE Trans Automat Contr 1974, 19:716-723.

36. Nylander JAA: MrModeltest v.2. Program distributed by author. Uppsala University: Evolutionary Biology Centre; 2004

37. Huelsenbeck JP, Ronquist F: MRBAYES: Bayesian inference of phylogenetic trees. Bioinformatics 2001, 17:754-755.

38. Marshall DC, Simon C, Buckley TR: Accurate branch length estimation in partitioned Bayesian analyses requires accommodation of amongpartition rate variation and attention to branch length priors. Syst Biol 2006, 55:993-1003.

39. Nylander JAA, Ronquist F, Huelsenbeck JP, Nieves-Aldrey JL: Bayesian phylogenetic analysis of combined data. Syst Biol 2004, 53:47-67.

40. Brandley MC, Schmitz A, Reeder TW: Partitioned Bayesian analyses, partition choice, and the phylogenetic relationships of scincid lizards. Syst Biol 2005, 54:373-390.

41. Kass RE, Raftery AE: Bayes factors. J Am Stat Assoc 1995, 90:773-795.

42. Xie W, Lewis PO, Fan Y, Kuo L, Chen M-H: Improving Marginal Likelihood estimation for Bayesian phylogenetic model selection. Syst Biol 2011, 60:150-160

43. Neal RM: Contribution to the discussion of "Approximate Bayesian inference with the weighted likelihood bootstrap" by Newton MA, Raftery AE. J R Stat Soc Ser A (Methodological) 1994, 56:41-42.

44. Fan $Y$, Wu R, Chen M-H, Kuo L, Lewis PO: Choosing among partition models in Bayesian phylogenetics. Mol Biol Evol 2011, 28:523-532.
45. Felsenstein J: Confidence-limits on phylogenies-an approach using the bootstrap. Evolution 1985, 39:783-791.

46. Bremer K: The limits of amino-acid sequence data in Angiosperm phylogenetic reconstruction. Evolution 1988, 42:795-803.

47. Bremer K: Branch support and tree stability. Cladistics 1994, 10:295-304

48. Baker RH, DeSalle R: Multiple sources of character information and the phylogeny of Hawaiian Drosophilids. Syst Biol 1997, 46:654-673.

49. Gatesy J, O'Grady P, Baker RH: Corroboration among data sets in simultaneous analysis: hidden support for phylogenetic relationships among higher level artiodactyl taxa. Cladistics 1999, 15:271-313.

50. Sorenson MD, Franzosa EA. TreeRot, Version 3. 2007. Boston, MA, Boston University. [http://people.bu.edu/msoren/TreeRot.html]

51. Peakall R, Smouse PE: GENALEX 6: genetic analysis in Excel. Population genetic software for teaching and research. Mol Ecol Notes 2006, 6:288-295.

52. Farrell BD: Evolutionary assembly of the milkweed fauna: cytochrome oxidase I and the age of Tetraope beetles. Mol Phylogenet Evol 2001, 18:467-478.

53. Papadopoulou A, Anastasiou I, Vogler AP: Revisiting the insect mitochondrial molecular clock: the Mid-Aegean Trench calibration. $\mathrm{Mol}$ Biol Evol 2010, 27:1659-1672.

54. Drummond AJ, Rambaut A: BEAST: Bayesian evolutionary analysis by sampling trees. BMC Evol Biol 2007, 7:214.

55. Rambaut A, Drummond AJ. Tracer, Version 1.5. 2007. [http://beast.bio.ed.ac. uk/Tracer]

56. Pons J, Barraclough TG, Gomez-Zurita J, Cardoso A, Duran DP, Hazell S, Kamoun S, Sumlin WD, Vogler AP: Sequence-based species delimitation for the DNA taxonomy of undescribed insects. Syst Biol 2006, 55:595-609.

57. Paradis E, Claude J, Strimmer K: APE: Analyses of phylogenetics and evolution in R language. Bioinformatics 2004, 20:289-290.

58. Rokas A, Nylander JAA, Ronquist F, Stone GN: A maximum-likelihood analysis of eight phylogenetic markers in gallwasps (Hymenoptera: Cynipidae): implications for insect phylogenetic studies. Mol Phylogenet Evol 2002, 22:206-219.

59. Brower AVZ: Problems with DNA barcodes for species delimitation: 'ten species' of Astraptes fulgerato reassessed (Lepidoptera: Hesperiidae). Syst Biodivers 2006, 4:127-132

60. Simonsen TJ, Wahlberg N, Brower AVZ, de Jong R: Morphology, molecules and fritillaries: approaching a stable phylogeny for Argynnini (Lepidoptera: Nymphalidae). Insect Syst Evol 2006, 37:405-418.

61. Buckley TR, Cordeiro M, Marshall DC, Simon C: Differentiating between hypotheses of lineage sorting and introgression in New Zealand alpine cicadas (Maoricicad Dugdale). Syst Biol 2006, 55:411-425.

62. Maddison WP, Knowles LL: Inferring phylogeny despite incomplete lineage sorting. Syst Biol 2006, 55:21-30.

63. Hovemann B, Richter S, Walldorf U, Cziepluch C: 2 genes encode related cytoplasmic elongation-factors 1-alpha (EF-1-Alpha) in Drosophila melanogaste with continuous and stage-specific expression. Nucleic Acids Res 1988, 16:3175-3194.

64. Danforth BN, Ji SQ: Elongation factor-1 alpha occurs as two copies in bees: implications for phylogenetic analysis of EF-1 alpha sequences in insects. Mol Biol Evol 1998, 15:225-235.

65. Monaghan MT, Gattolliat JL, Sartori M, Elouard JM, James H, Derleth P, Glaizot O, de Moor F, Vogler AP: Trans-oceanic and endemic origins of the small minnow mayflies (Ephemeroptera, Baetidae) of Madagascar. Proc $R$ Soc Lond B Biol Sci 2005, 272:1829-1836.

66. Swartz ER, Skelton PH, Bloomer P: Sea-level changes, river capture and the evolution of populations of the Eastern Cape and fiery redfins (Pseudobarbus afe and Pseudobarbus phlegetho, Cyprinidae) across multiple river systems in South Africa. J Biogeogr 2007, 34:2086-2099.

67. Swartz ER, Skelton PH, Bloomer P: Phylogeny and biogeography of the genus Pseudobarbu (Cyprinidae): shedding light on the drainage history of rivers associated with the Cape Floristic Region. Mol Phylogenet Evol 2009, 51:75-84.

68. Hughes JM, Bunn SE, Kingston DM, Hurwood DA: Genetic differentiation and dispersal among populations of Paratya australiensi (Atyidae) in rain-forest streams in southeast Queensland, Australia. J North Am Benthol Soc 1995, 14:158-173.

69. Hughes JM, Bunn SE, Hurwood DA, Choy S, Pearson RG: Genetic differentiation among populations of Caridina zebr (Decapoda: Atyidae) in tropical rainforest streams, northern Australia. Freshw Biol 1996, 36:289-296. 
70. Price BW, Barker NP, Villet MH: Patterns and processes underlying evolutionary significant units in the Platypleura stridul L. species complex (Hemiptera: Cicadidae) in the Cape Floristic Region, South Africa. Mol Ecol 2007, 16:2574-2588.

71. Price BW, Barker NP, Villet MH: A watershed study on genetic diversity: phylogenetic analysis of the Platypleura plumos (Hemiptera: Cicadidae) complex reveals catchment-specific lineages. Mol Phylogenet Evol 2010, 54:617-626.

72. Jackson JK, Resh VH: Variation in genetic-structure among populations of the caddisfly Helicopsyche boreali from 3 streams in northern California, USA. Freshw Biol 1992, 27:29-42.

73. Wishart MJ, Hughes JM: Exploring patterns of population subdivision in the net-winged midge, Elporia barnard (Diptera: Blephariceridae), in mountain streams of the south-western Cape, South Africa. Freshw Biol 2001, 46:479-490.

74. de Moor FC: A survey of Trichoptera from the tributaries of the Doring and mainstream Olifants Rivers, Cederberg, South Africa with implications for conservation. Zoosymposia 2011, 5:350-359.

75. Hughes JM, Bunn SE, Hurwood DA, Cleary C: Dispersal and recruitment of Tasiagma ciliat (Trichoptera: Tasimiidae) in rainforest streams, southeastern Australia. Freshw Biol 1998, 39:117-127.

76. Hughes JM, Mather PB, Sheldon AL, Allendorf FW: Genetic structure of the stonefly, Yoraperla brevi, populations: the extent of gene flow among adjacent montane streams. Freshw Biol 1999, 41:63-72.

77. Wishart MJ: Catchments as conservation units for riverine biodiversity. South Afr J Aquat Sci 2000, 25:169-174.

78. Daniels SR, Stewart BA, Burmeister L: Geographic patterns of genetic and morphological divergence amongst populations of a river crab (Decapoda, Potamonautidae) with the description of a new species from mountain streams in the Western Cape, South Africa. Zool Scr 2001, 30:181-197.

79. Daniels S, Stewart BA, Gouws G, Cunningham M, Matthee CA: Phylogenetic relationships of the southern African freshwater crab fauna (Decapoda: Potamonautidae: Potamonaute) derived from multiple data sets reveal biogeographic patterning. Mol Phylogenet Evol 2002, 25:511-523.

80. Daniels SR, Gouws G, Stewart BA, Coke M: Molecular and morphometric data demonstrate the presence of cryptic lineages among freshwater crabs (Decapoda: Potamonautidae: Potamonaute) from the Drakensberg Mountains, South Africa. Biol J Linn Soc 2003, 78:129-147.

81. Daniels SR, Gouws G, Crandall KA: Phylogeographic patterning in a freshwater crab species (Decapoda: Potamonautidae: Potamonaute) reveals the signature of historical climatic oscillations. J Biogeogr 2006, 33:1538-1549.

82. Gouws G, Stewart BA, Daniels SR: Cryptic species within the freshwater isopod Mesamphisopus capensi (Phreatoicidea: Amphisopodidae) in the Western Cape, South Africa: allozyme and 12S rRNA sequence data and morphometric evidence. Biol J Linn Soc 2004, 81:235-253.

83. Siesser WG: Late Miocene origin of the Benguela upswelling system off northern Namibia. Science 1980, 208:283-285.

84. Goldblatt P: Floristic diversity in the Cape Flora of South Africa. Biodivers Conserv 1997, 6:359-377.

85. Dynesius M, Jansson R: Evolutionary consequences of changes in species' geographical distributions driven by Milankovitch climate oscillations. Proc Natl Acad Sci U S A 2000, 97:9115-9120.

86. Partridge TC, Scott L, Hamilton JE: Synthetic reconstructions of southern African environments during the Last Glacial Maximum (21-18 kyr) and the Holocene Altithermal (8-6 kyr). Quat Int 1999, 57-8:207-214.

87. Tolley KA, Braae A, Cunningham M: Phylogeography of the Clicking Stream Frog Strongylopus grayi (Anura, Pyxicephalidae) reveals cryptic divergence across climatic zones in an abundant and widespread taxon. Afr J Herpetol 2010, 59:17-32.

88. Johnson RK, Wiederholm T, Rosenberg DM: Freshwater biomonitoring using individual organisms, populations, and species assemblages of benthic macroinvertebrates. In Freshwater biomonitoring and benthic macroinvertebrates. Edited by Rosenberg DM, Resh VH. New York: Chapman and Hall; 1993:88-91.
89. Allan JD: Streamwater chemistry. In Stream Ecology. Structure and function of running waters. London: Chapman and Hall; 1995:23-43.

90. Visser DJL: Geological map of the Republics of South Africa, Transkei, Bophuthatswana, Venda and Ciskei and the Kingdoms of Lesotho and Swaziland. South Africa: Department of Minerals and Energy Affairs; 1984

91. Barber-James HM, Sartori M, Gattolliat J-L, Webb JM: Checklist of mayflies of the world. 2011. [http://fada.biodiversity.be/group/show/35]

doi:10.1186/1471-2148-12-26

Cite this article as: Pereira-da-Conceicoa et al.: Cryptic variation in an ecological indicator organism: mitochondrial and nuclear DNA sequence data confirm distinct lineages of Baetis harrisoni Barnard (Ephemeroptera: Baetidae) in southern Africa. BMC Evolutionary Biology 2012 12:26.

\section{Submit your next manuscript to BioMed Central and take full advantage of:}

- Convenient online submission

- Thorough peer review

- No space constraints or color figure charges

- Immediate publication on acceptance

- Inclusion in PubMed, CAS, Scopus and Google Scholar

- Research which is freely available for redistribution 